\title{
Effect of F Content on the Protection of Melted Magnesium Alloy
}

\author{
LIPING ZHANG ${ }^{*}$, HONGLIANG LIN ${ }^{1,5^{*}}$, HUIZHU YANG ${ }^{2}$, AN SUN ${ }^{3}$, WEI ZHANG ${ }^{1}$, \\ XIAO CHEN ${ }^{4}$ \\ ${ }^{1}$ Key Laboratory of Expressway Construction Machinery of Shaanxi Province, Chang'an University, Xi'an,China \\ ${ }^{2}$ State Key Laboratory for Manufacturing Systems Engineering, Xi'an Jiaotong University, Xi'an, China \\ ${ }^{3}$ College of Engineering and Applied Sciences, Nanjing University, Nanjing 210093, China \\ ${ }^{4}$ College of Mechanical Engineering and Automation, Fuzhou University, Fu Zhou, China \\ ${ }^{5}$ Shaanxi College of Communication Technology, Xi'an, China
}

Abstract: The protection of molten AZ91D alloy in the cover gases containing sulfur decomposed by $\mathrm{FeS}_{2}$ and fluorine produced by $\mathrm{HFC}-134 \mathrm{a}$ at $730^{\circ} \mathrm{C}$ was investigated in this paper. The surface films were analyzed by scanning electron microscopy (SEM), energy dispersive spectrometer (EDS), X-ray diffraction (XRD) and X-ray photoelectron spectrometer (XPS). It is revealed that the cover gases containing sulfur decomposed by $\mathrm{FeS}_{2}$ and fluorine produced by $\mathrm{HFC}-134$ a can protect the molten AZ91D alloy well. HFC-134a whose volume fraction is $0.04 \%-0.1 \%$ mixed with gas containing sulfur by adding $\mathrm{FeS}_{2} 0.5 \mathrm{~g}$ per 30 minutes and holding the melting temperature at $730^{\circ} \mathrm{C}$ for 30 min can protect the molten AZ91D alloy. The bigger the volume fraction of $\mathrm{HFC}-134 \mathrm{a}$, the better the effect. The protected film is formed of $\mathrm{MgO}, \mathrm{MgF}_{2}$ and small amount $\mathrm{MgS}$.

Keywords: Magnesium alloy, SEM, FeS2, HFC-134a, Oxidation.

\section{Introduction}

As a structural material, magnesium alloys are more and more widely used in aerospace, automotive, electronics, the field of national defense and bio-medical applications due to their good properties, rich reserves and production cost decreased with the progress of technology. However, molten magnesium oxidizes readily in an atmosphere containing oxygen, often leading to combustion on the melt surface [1]. To address this issue, it is necessary to protect the melt by the cover gas over the melts. $\mathrm{SF}_{6}$ contained in common gases is no longer acceptable environmentally due to its extremely high greenhouse effect as well as a very long retention period in the atmosphere and substituted by the other atmosphere of gases containing sulfur and fluorine.

Many researchers have reported that 1,1,1,2-tetrafluoroethane (HFC-134a) is a possible substitute for $\mathrm{SF}_{6}$ and $\mathrm{HFC}-134 \mathrm{a}$ can provide effective protection for magnesium and some magnesium alloy melts [2,3]. Moreover, the protection effects of $\mathrm{SO}_{2}$ mixed with carrier gases also have been studied by a few researchers which found that $\mathrm{MgSO}_{4}$ also formed in the protective film and the formation of the film might be related to the formation of $\mathrm{MgSO}_{4}$ [4-8]. $\mathrm{FeS}_{2}$, a kind of pyrites, is decomposed at a high temperature and elemental sulfur created as well as sulfur dioxide $[9,10]$ and has a lower cost compared with $\mathrm{SO}_{2}$.

In this paper, the protection of molten magnesium alloys AZ91D in the cover gases containing sulfur decomposed by $\mathrm{FeS}_{2}$ and fluorine produced by HFC-134a was investigated. With the different contents of sulfur and fluorine, the micro-structure and composition of the surface films were examined, and the thermodynamic properties of the system were also investigated.

*email: liping.zhang@bk.ru,77302385@qq.com 


\section{Materials and methods}

The chemical composition of the material AZ91D magnesium alloy studied at present in weight percent was $9.21 \% \mathrm{Al}, 0.67 \% \mathrm{Zn}, 0.203 \% \mathrm{Mn}, 0.0007 \% \mathrm{Ni}, 0.002 \% \mathrm{Fe}, 0.0006 \% \mathrm{Cu}$, and $\mathrm{Mg}$ balance.

In order to reduce the influence of surface films, the surface oxide film of magnesium alloy block $(130 \mathrm{~g}-170 \mathrm{~g})$ was cut and removed before the experiment. The chemical composition of $\mathrm{FeS}_{2}$ in this experiment was analyzed by EDS and determined as $4.24 \% \mathrm{O}, 0.86 \% \mathrm{Mg}, 2.79 \% \mathrm{Si}, 47.71 \% \mathrm{~S}, 44.4 \% \mathrm{Fe}$ in weight percent. The protective effect using different sizes $\mathrm{FeS}_{2}$ were compared and determine to use $\mathrm{FeS}_{2}$ with $120 \sim 180 \mu \mathrm{m}$ in this experiment.

Figure 1 shows the installation and the schematic diagram of open furnace of $5 \mathrm{~L}$ used in this experiment. To control the melting atmosphere, a certain count of $\mathrm{FeS}_{2}$ was put around the crucible with magnesium alloy specimen at the bottom of the open furnace from the filling tube for every 30 min. At the same time, the other controlled mixed gases containing HFC-134a flew through a flow meter and fed into the furnace. The cover gases containing different HFC-134a or air contents were shown in Table 1.

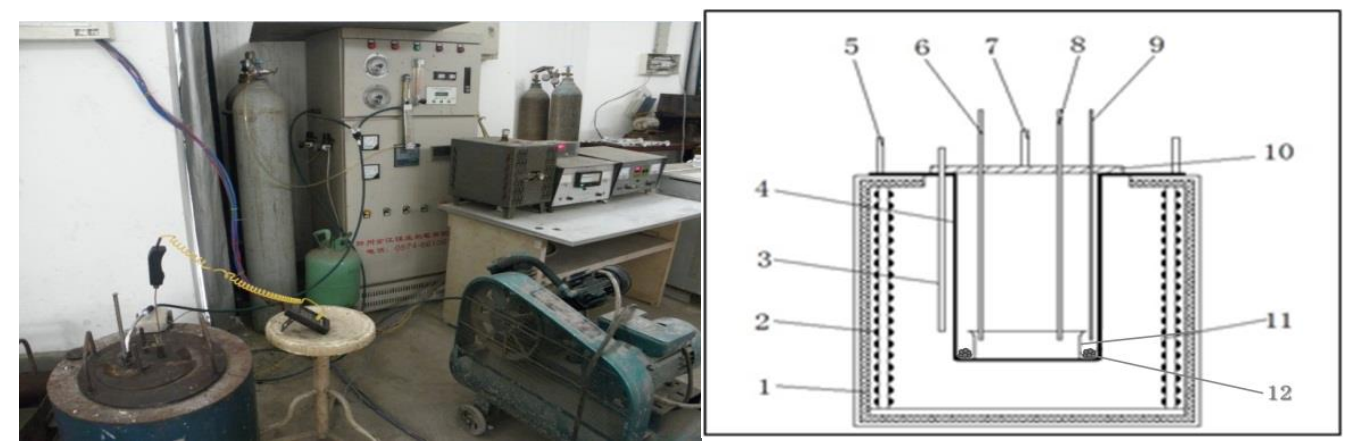

Figure 1. a. Photograph of the installation used in this experiment b. Schematic diagram of apparatus sectional view of the furnace. 1.Heat-barrier materials 2.Resistance wire 3.Thermocouple of temperature control 4.Melting furnace 5.Handle of melting furnace 6.Thermocouple of temperature measurement 7.Handle of furnace cover 8.Inlet pipe 9.Filling tube 10.Furnace cover 11.Crucible. 12. $\mathrm{FeS}_{2}$ 。 The cover gases pumped in the furnace to replace the air before the experiment for $30 \mathrm{~min}$. Proper amount of $\mathrm{FeS}_{2}$ was added around the crucible with magnesium alloy specimen at the bottom of the furnace. Then began to heat to $730^{\circ} \mathrm{C}$ with the speed of $25^{\circ} \mathrm{C} / \mathrm{min}$. The $\mathrm{FeS}_{2}$ was added from filling

sleeve tube according to set time and amount until the end of the experiment .Cut the volume of $10 \mathrm{~mm} \times 10 \mathrm{~mm} \times 8 \mathrm{~mm}$ out of the specimen to analyze and test. Phase analysis of the protective film was by XRD and morphology and composition by EXEM and accessory of EDS.

\section{Results and discussions}

\subsection{The Effect of HFC-134a Content on Protective Effect}

Figure 2 shows the effect of HFC-134a content on protective effect of molten AZ91D alloy with adding $\mathrm{FeS}_{2} 0.5 \mathrm{~g}$ per $30 \mathrm{~min}$ and holding the melting temperature at $730^{\circ} \mathrm{C}$ for 30 minutes. When volume fraction of HFC-134a was $0 \%$, melting magnesium was protected only by proper amount $\mathrm{FeS}_{2}$ and some cauliflower-like oxides formed on the surface (Figure 2a). The effect was not good. With volume fraction of HFC-134a $0.04 \%$, a little of the oxides were formed at individual position and effect is common (Figure $2 \mathrm{~b}$ ). With volume fraction of HFC-134a $0.07 \%$, cracking was formed on the film substituting oxides and effect is common (Figure $2 \mathrm{c}$ ). With volume fraction of HFC-134a $0.1 \%$, a silver-gray dense crack-free protective film with no crack was formed on the surface and the effect is good (Figure 2d). In a word, protective effect is better with higher volume fraction of HFC-134a under the condition that $\mathrm{FeS}_{2}$ was added $0.5 \mathrm{~g}$ per $30 \mathrm{~min}$. 
Table 1. The parameters and the protection effect of samples

\begin{tabular}{cccc}
\hline Samples & Weight of $\mathbf{F e S}_{\mathbf{2}}(\mathbf{g})$ per 30 min & Volume fraction of HFC-134a/ $\%$ & Protection effect \\
\hline 1 & 0.5 & 0 & Not protected \\
\hline 2 & 0.5 & 0.04 & Partly protected \\
\hline 3 & 0.5 & 0.07 & Partly protected \\
\hline 4 & 0.5 & 0.1 & Fully protected \\
\hline
\end{tabular}

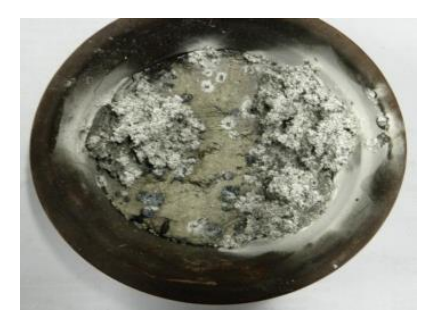

a. $0 \% \mathrm{HFC}-134 \mathrm{a}+0.5 \mathrm{gFeS} 2$

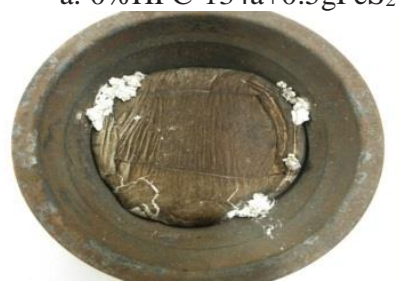

b. $0.04 \% \mathrm{HFC}-134 \mathrm{a}+0.5 \mathrm{gFeS}_{2}$

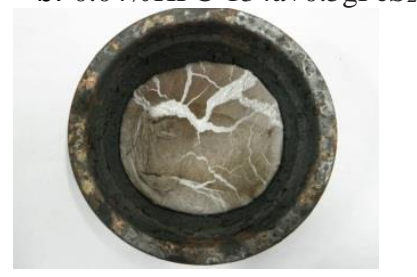

c. $0.07 \% \mathrm{HFC}-134 \mathrm{a}+0.5 \mathrm{gFeS} 2$

Figure 2. The effect of HFC-134a

content on protective effect

$\left(0.5 \mathrm{gFeS} / 30 \mathrm{~min}\right.$-air- $730^{\circ} \mathrm{C}$-holding $\left.30 \mathrm{~min}\right)$

\subsection{Morphology of Surface Film}

Figure 3 shows the different surface film morphology of molten AZ91D alloy protected by different HFC-134a content with adding $\mathrm{FeS}_{2} 0.5 \mathrm{~g}$ per $30 \mathrm{~min}$ and holding the melting temperature at $730^{\circ} \mathrm{C}$ for $30 \mathrm{~min}$. With volume fraction of $\mathrm{HFC}-134 \mathrm{a} 0.04 \%$, a part of the matrix was exposed and the surface film was not complete (Figure 3a). With volume fraction of HFC-134a $0.07 \%$, most of the matrix was covered by protected film with a little cracking and the surface film was become compact (Figure 3b). With volume fraction of HFC-134a 0.1\%, compact protective film with no crack was formed and covered the matrix completely with a good effect (Figure $3 \mathrm{c}$ ). 

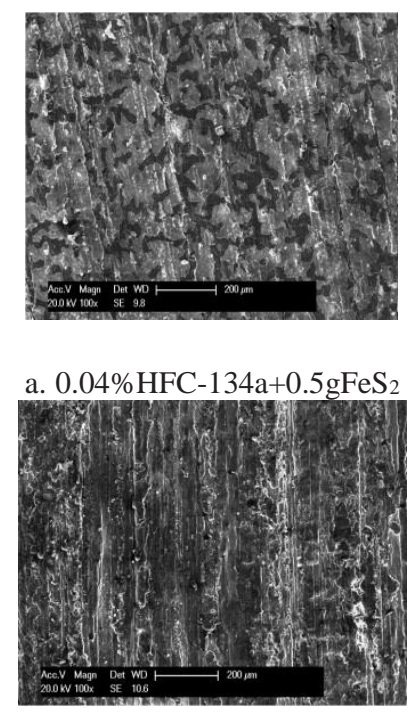

b. $0.07 \% \mathrm{HFC}-134 \mathrm{a}+0.5 \mathrm{gFeS} 2$

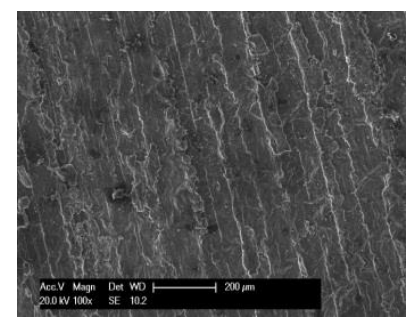

c. $0.1 \% \mathrm{HFC}-134 \mathrm{a}+0.5 \mathrm{gFeS} 2$

Figure 3. Morphology of the surface film tested by EXEM $\left(0.5 \mathrm{~g} \mathrm{FeS}_{2} / 30 \mathrm{~min}\right.$-air- $730^{\circ} \mathrm{C}$-holding $\left.30 \mathrm{~min}\right)$

\subsection{Compositions of Surface Film}

Table 2 shows the effect of HFC-134a content on composition of surface film with adding $\mathrm{FeS}_{2}$ $0.5 \mathrm{~g}$ per $30 \mathrm{~min}$ and holding the melting temperature at $730^{\circ} \mathrm{C}$ for $30 \mathrm{~min}$. Surface film was tested by EDS and average composition can be determined. The depth tested by EDS can be greater than the thickness of surface film which was thin. Although magnesium matrix information was tested, reaction degree can be judged. With volume fraction of HFC-134a/\% increasing, the percentage content of $\mathrm{F}$ increased, $\mathrm{O}$ decreased obviously and $\mathrm{S}$ decreased also. The content of $\mathrm{MgO}$ and $\mathrm{MgS}$ decreased and $\mathrm{MgF}_{2}$ increased in the film judged by the percentage content of $\mathrm{O}, \mathrm{F}$ and $\mathrm{S}$.

Table 2. Different compositions of surface film with the change of HFC-134a content Sample parameters:AZ91D alloy, $0.5 \mathrm{~g} \mathrm{FeS}_{2} / 30 \mathrm{~min}$-air- $730^{\circ} \mathrm{C}-30 \mathrm{~min}$

\begin{tabular}{ccccc}
\hline Volume fraction of HFC-134a/\% & $\mathbf{O} / \%$ & $\mathrm{~F} / \%$ & $\mathrm{~S} / \%$ & $\mathrm{Mg} / \%$ \\
\hline $0.04 \%$ & 26.05 & 10.55 & 3.14 & 53.26 \\
\hline $0.07 \%$ & 20.15 & 15.06 & 2.63 & 58.22 \\
\hline $0.1 \%$ & 18.93 & 18.34 & 1.38 & 52.88 \\
\hline
\end{tabular}




\subsection{Analysis of XRD and XPS}

The protected film contains not only $\mathrm{Mg}, \mathrm{F}, \mathrm{O}$ and $\mathrm{S}$, but also other elements determined by the testing of morphology and compositions. Compounds can be determined by XRD analysis. Figure 4 shows the XRD analysis result of the AZ91D alloy sample. The melt magnesium alloy was protected by mixed gas containing $0.1 \% \mathrm{HFC}-134 \mathrm{a}$ and sulfur decomposed by $\mathrm{FeS}_{2}$ which was added $0.5 \mathrm{~g}$ per 30 minutes. Heat the melting to the temperature at $730^{\circ} \mathrm{C}$ and hold for 30 minutes. It can be concluded that the protected film was formed of $\mathrm{MgO}, \mathrm{MgF}_{2}$ and a small amount of $\mathrm{MgS}$. The peak of $\mathrm{Mg}$ is obvious and caused by matrix with thin surface film (Figure 4).

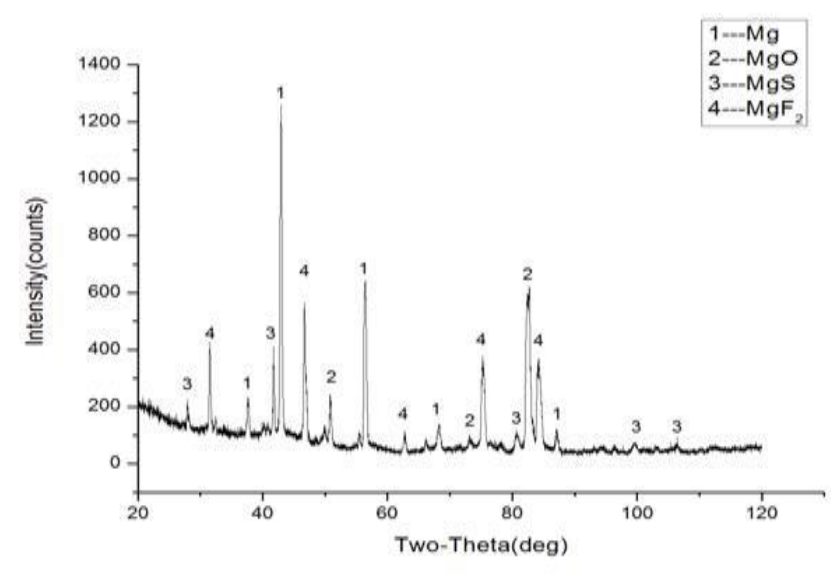

Figure 4. XRD analysis of the protected film

Figure 5 shows the whole pattern of surface film and the film sputtered for 500s by XPS. The sample melted in the protective gas containing $0.1 \%$ HFC-134a and sulfur decomposed by $\mathrm{FeS}_{2}$ which was added $0.5 \mathrm{~g}$ per 30 minutes. The surface film contains $\mathrm{Mg}, \mathrm{O}, \mathrm{F}, \mathrm{S}$ and a little C. Figure 6 shows the Mg1sXPS spectra of film from the same sample. 3 peaks can be obtained by fitting the high resolution spectra. It means $\mathrm{Mg}$ elements existed in 3 states in the protected film. It can be concluded that the main elements $\mathrm{Mg}, \mathrm{O}, \mathrm{S}$ and $\mathrm{F}$ in the film correspond to peaks of $\mathrm{MgO}, \mathrm{MgS}$ and $\mathrm{MgF}_{2}$.

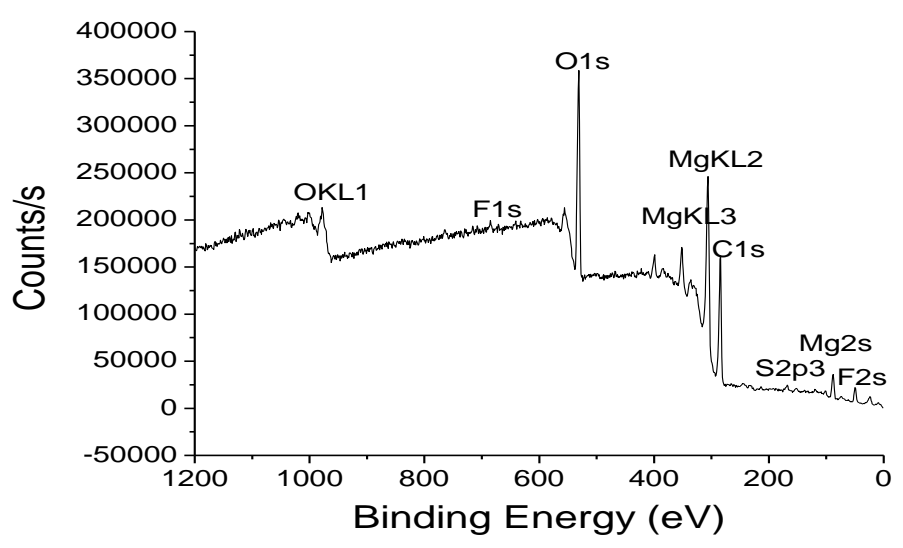

Figure 5. The whole pattern of surface film determined by XPS $\left(730^{\circ} \mathrm{C}-30 \mathrm{~min}-\right.$ air- $0.5 \mathrm{~g} \mathrm{FeS} / 30 \mathrm{~min}+0.1 \%$ HFC-134a) 


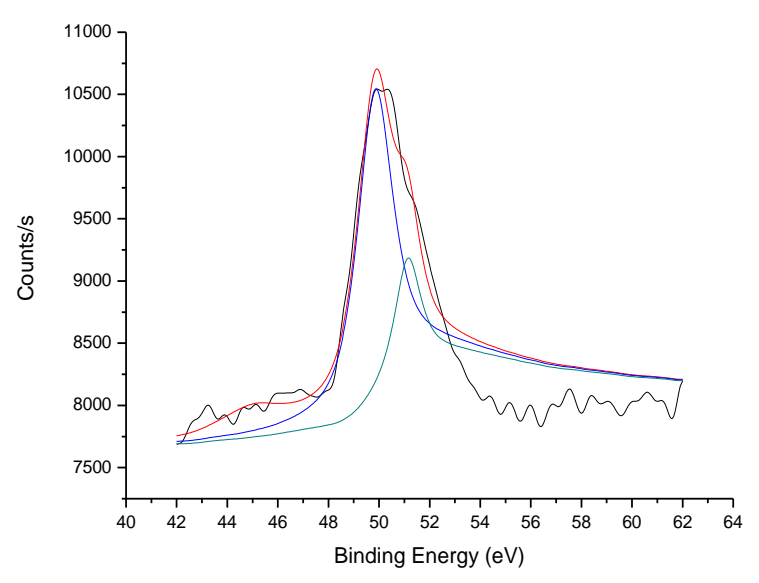

Figure 6. Mg1sXPS spectra of the surface film

\section{Conclusions}

$\left(730^{\circ} \mathrm{C}-30 \mathrm{~min}-\right.$ air- $0.5 \mathrm{gFeS}_{2} / 30 \mathrm{~min}+0.1 \% \mathrm{HFC}-134 \mathrm{a}$

Finally, the basic questions posed above are then discussed and conclusions are drawn.

(1) The cover gases containing sulfur decomposed by $\mathrm{FeS}_{2}$ and fluorine produced by HFC-134a can protect the molten AZ91D alloy well.

(2) Volume fraction of HFC-134a was $0.04 \%-0.1 \%$ mixed with gas containing sulfur by adding $\mathrm{FeS}_{2} 0.5 \mathrm{~g}$ per $30 \mathrm{~min}$ and holding the melting temperature at $730^{\circ} \mathrm{C}$ for $30 \mathrm{~min}$ can protect the molten AZ91D alloy. The bigger the volume fraction of HFC-134a, the better the effect.

(3) The protected film was formed of $\mathrm{MgO}, \mathrm{MgF}_{2}$ and small amount $\mathrm{MgS}$.

Acknowledgments: The Project was Supported by the Key Laboratory of Expressway Construction Machinery of Shaanxi Province (300102259513), the Fundamental Research Funds for the Central Universities of Chang'an University (Grant No. 300102258205), and Open Research Foundation of State Key Lab. of Digital Manufacturing Equipment and Technology in Huazhong University of Science and Technology. (Grant No. DMETKF2015015).

\section{References}

1. MIRAK, A., DAVIDSON, C. J., TAYLOR, J. A., Characterisation of fresh surface oxidation films formed on pure molten magnesium in different atmospheres. Corr. Sci., 52, 2010,1992-2000.

2. RICKETTS, N. J., CASHION, S. P., Hydrofluorocarbons as cover gases for magnesium melt protection, Magnesium Technology 2006[C]. Warrendale, USA. Min. Met. Mater. Soc., 2001, 31-36.

3. CASHION, S. P., RICKETTS, N. J., FROST, M. T., KORN, C. J., The protection of molten magnesium and its alloys during die-casting[C], The 8th Annual IMA Magnesium in Automotive Seminar. Aalen, GER. Int. Magnes. Assoc., 2000, 12-14.

4. FRUEHLING, J. F., Protective Atmospheres for Molten Magnesium [D]. Ph.D.Thesis. Univ. Michigan., 1970.

5. ARGO, D., LEFEBVRE, M., Magnesium Technology 2003 [M], TMS. San Diego, America., 2003, 15-21.

6. CASHION, S. P., The Use of Sulphur Hexa-uoride (SF6) for Protecting Molten Magnesium[D]. Ph.D. Thesis. Univ. Queensland., 1998.

7. PETTERSEN, G., VRELID, E., TRANELL, G., [M]. Eng.A. Mater. Sci., 332, 2002, 285-294.

8. WANG, X. F., XIONG, S. M., Mater. Chem. Phys., 135, 2012, 541-548.

9. ZENGHUI, W., HELIN, L., XIAOPENG, X., Study and Characteri-zation of Reduced Sulfur in Oxidation Process of Ferro Sulfide Compounds. Min. Metalurg., 18(1), 2009, 96-99. 
10. FEI, X., YONGMING, H., CHANGDONG, S., Decomposition Char-acteristics of Pyrite (FeS2) Particle under Combustion Condition. J. Combus. Sci. Technol., 6(3), 2000, 280-283.

11. Xu, Z., Chen, X., Meng, L., Yu, M., Li, L., Shi, W., Sample Consensus Model and Unsupervised Variable Consensus Model for Improving the Accuracy of a Calibration Model. Appl. Spect., 73(7), 2019, 747-758.

12. LEI, Z., GAO, H., CHANG, X., ZHANG, L., WEN, X., \& WANG, Y., An application of green surfactant synergistically metal supported cordierite catalyst in denitration of Selective Catalytic Oxidation. J. Clean. Prod., 249, 2020, 119307.

13. ZHANG, Y., ZHANG, X., LI, M., LIU, Z., Research on heat transfer enhancement and flow characteristic of heat exchange surface in cosine style runner. Heat and Mass Transfer, 55(11), 2019, 3117-3131.

14. LUPESCU, S., ISTRATE, B., MUNTEANU, C., MINCIUNA, M.G., FOCSANEANU, S., EARAR, K., Characterization of Some Master Mg-X System (Ca, Mn, Zr, Y) Alloys Used in Medical Applications. Rev.Chim., 68(6), 1310-1315.

Manuscript received: 20.03 .2020 